\title{
El reto de difundir el patrimonio cultural en Internet: perspectivas y experiencias
}

\author{
Francisco Javier García Marco \\ Universidad de Zaragoza (España)
}

\section{Resumen}

Se presentan los artículos que componen el número 2 del volumen 14 de la revista Scire: Organización y Representación del Conocimiento (jul.-dic. 2008), dedicado a las bibliotecas y servicios de información digital como instrumentos para difundir el patrimonio cultural, artístico y científico. Constituyen una variada muestra de la complejidad de los problemas que se plantean en el campo de la información y la documentación digital: código abierto, cooperación en la Red, preservación digital, evaluación de servicios digitales, derechos de autor y de copia, con énfasis en la utilización de las nuevas tecnologías de la información para la difusión del patrimonio artístico, cultural y científico.

Palabras clave: Gestión de la información. Gestión del conocimiento. Modelos de gestión. Latinoamérica.

\section{Abstract}

The articles published in the number 2 of the volume 14 of Scire (July-Dec. 2008) are presented, which are mainly devoted to digital libraries and information services as a tool to broadcast the cultural, artistic and scientific heritage. The papers examine the complexity of the problems that the digital environment poses: open code, using the Net to offer truly cooperative services, digital preservation, digital services assessment, copyright, with an emphasis in the utilization of the new information and communication technologies to disseminate the information about the artistic, cultural and scientific heritage.

Keywords: Information management. Knowledge management. Management models. Latin America.

\section{Introducción}

Este segundo número del volumen 14 de la revista Scire: Organización y Representación del Conocimiento (en.-jun. 2008) está formado por artículos que abordan diversos retos planteados por la revolución telemática a los profesionales y a los servicios de información y documentación. Tratan desde aspectos tecnológicos

Scire. $14: 2$ (jul.-dic. 2008) 9-12. ISSN 1135-3716. 
como la web social y el código libre hasta cuestiones de gestión y evaluación de servicios de información relacionados con bibliotecas, archivos y sitios web.

\section{Presentación de los artículos}

El primer artículo es un interesantísimo estudio de Alan Gilchrist (2008) sobre la Web 2.0 y sus implicaciones para el desarrollo de la Ciencia de la Información y las profesiones de la información y la documentación, titulado "Contexto y consenso". Además de realizar una revisión de las tecnologías, el trabajo destaca por abordar las cuestiones más filosóficas, relacionadas con las nuevas formas de entender la empresa, la gestión de las organizaciones y, en general, la organización de la sociedad en la era de la información. Como resultado de su reflexión, Alan Gilchrist traza las paradojas en las que se desarrolla el debate actual sobre el impacto de la Red y de la Web 2.0 en particular: gestión y gestión del conocimiento, liderazgo informado y "sabiduría de las masas", gestión del conocimiento y gestión de la información, y, finalmente, desbordamiento informacional y desbordamiento tecnológico.

El segundo artículo aborda los "Programas de código libre (GNU) para la recuperación de información”. En él, Carlos G. Figuerola, José Luis Alonso Berrocal, Angel F. Zazo y Emilio Rodríguez (2008) reflexionan sobre la historia, el desarrollo y las aportaciones del software libre, y presentan y analizan cuatro ejemplos notables desarrollados en los últimos años: DataPark, Lucene y Nutch, SWISH-e y HTDIG.

Seguidamente, se presenta el artículo de Alfonso López Yepes (2008) "Filmotecas y archivos fílmicos en línea: producción, difusión, interconexión y posicionamiento en Internet". Se trata de un trabajo que aborda en profundidad la situación de las filmotecas y los archivos fílmicos, fundamentalmente en España pero sin dejar de lado algunos ejemplos señeros de nuestro entorno internacional, contextualizando el problema en los desarrollos más innovadores que se estaban produciendo en 2006 en las diferentes tecnologías informáticas y telemáticas. Alfonso López Yepes sugiere potenciar la colaboración informal y formal entre las instituciones en el marco de las redes nacionales, europeas e internacionales, y aprovechar las múltiples vías de financiación que se han abierto para la generación de contenidos digitales.

El cuarto trabajo, de Alejandro Delgado (2008), se plantea el análisis de "El arte digital como estudio de caso de los problemas asociados a la conservación de documentos de archivo en el actual entorno tecnológico". A través del problema del arte digital, el autor muestra las dificultades que se plantean para la conservación de los documentos digitales y los límites del estado actual de la cuestión. El autor no se queda en el simple planteamiento de los escollos existentes, sino que aborda el problema desde una sólida base teórica archivística. 
A continuación, Francisco Javier Martínez Méndez (2008), en su artículo "Análisis y medida de la ubicuidad y usabilidad de los portales web de las universidades españolas", plantea una metodología para el análisis de la ubicuidad, visibilidad, organización de los contenidos, presentación formal y servicios de fidelización de estos portales web, que se sintetiza en un indicador global. El estudio es muy interesante y se desarrolla con todas las exigencias de replicabilidad que el método científico exige.

El trabajo de Almudena Knecht Cristóbal (2008) aborda los retos que la revolución de Internet ha planteado a la profesión bibliotecaria y se apoya en la experiencia concreta de digitalización y difusión por Internet realizada por la biblioteca del Centro de Estudios Avanzados en Ciencias Sociales (CEACS) del Instituto Juan March. Para Almudena Knecht, el profesional de la información tiene una gran experiencia en procesos críticos de gestión de la información y posee un conocimiento excelente de las necesidades y comportamientos de información de los usuarios, lo que le aporta cierta ventaja en el nuevo entorno socioprofesional, siempre que acepte incorporarse a los procesos de innovación tecnológica y organizacional y entienda el trabajo informacional como una labor interdisciplinar y de equipo.

Jesús Francisco García Pérez (2008) analiza "El derecho de autor y la industria editorial en México y España: influencia y comportamiento en el entorno virtual" y muestra cómo la legislación va por detrás del proceso de cambio tecnológico, económico y social, así como los esfuerzos de autores, editores y bibliotecas por adaptarse al nuevo ambiente digital.

N. Fabiola Rosales, Marlene Bauste y Baltazar E. Porras Cardozo (2008) presentan el proyecto de "La Biblioteca Digital de la Arquidiócesis de Mérida (Venezuela) y el modelo de metadatos: una propuesta para la difusión de los bienes culturales de la Iglesia católica en la Web". Se trata de un interesantísimo estudio de caso realizado sobre una institución que destaca por la amplitud de su patrimonio cultural y artístico.

La comunicación de Raquel Sardá Sánchez y María F. Sánchez Hernández (2008) sobre "Los procesos de catalogación y difusión de la información en el Museo Cerralbo de Madrid" da cuenta de una novedosa experiencia de digitalización y publicación digital de los fondos de dicho museo, que se caracteriza por su enfoque holístico de la difusión de los fondos museísticos en Internet.

Finalmente, José Luis Cárceles Andreu, Isabel Andreu Felipe, Carmen María Brugarolas Ros y Concepción Dolores Alcázar Ruiz analizan brevemente algunos aspectos prácticos de la "Legislación aplicable a los servicios electrónicos en unidades documentales".

Scire. $14: 2$ (jul.-dic. 2008) 9-12. ISSN 1135-3716. 


\section{Referencias}

Cárceles Andreu, José Luis; Andreu Felipe, Isabel; Brugarolas Ros, Carmen María; Alcázar Ruiz, Concepción Dolores (2008). Legislación aplicable a los servicios electrónicos en unidades documentales. // Scire: Representación y Organización del Conocimiento. $14: 2$ (jul.-dic. 2008) 161-165.

Delgado Gómez, Alejandro (2008). El arte digital como estudio de caso de los problemas asociados a la conservación de documentos de archivo en el actual entorno tecnológico. // Scire: Representación y Organización del Conocimiento. 14:2 (jul.-dic. 2008) 65-85.

Figuerola, Carlos G.; Alonso Berrocal, José Luis; Zazo Rodríguez, Ángel F.; Rodríguez, Emilio (2008). Programas de código libre (GNU) para la recuperación de información. // Scire: Representación y Organización del Conocimiento. 14:2 (jul.-dic. 2008) 31-40.

García Pérez, Jesús Francisco (2008). El derecho de autor y la industria editorial en México y España: influencia y comportamiento en el entorno virtual. // Scire: Representación y Organización del Conocimiento. 14:2 (jul.-dic. 2008) 119-130.

Gilchrist, Alan (2008). Context and consensus. // Scire: Representación y Organización del Conocimiento. 14:2 (jul.-dic. 2008) 13-29.

Knecht Cristóbal, Almudena (2008). La búsqueda de la innovación en proyectos bibliotecarios: el valor de la colaboración interdisciplinar. // Scire: Representación y Organización del Conocimiento. 14:2 (jul.-dic. 2008) 107-118.

López Yepes, Alfonso (2008). Filmotecas y archivos fílmicos en línea: producción, difusión, interconexión y posicionamiento en Internet. // Scire: Representación y Organización del Conocimiento. 14:2 (jul.-dic. 2008) 41-64.

Martínez Méndez, Francisco Javier (2008). Análisis y medida de la ubicuidad y usabilidad de los portales web de las universidades españolas. // Scire: Representación y Organización del Conocimiento. 14:2 (jul.-dic. 2008) 87-106.

Rosales, N. Fabiola; Bauste, Marlene; Porras Cardozo, Baltazar E. (2008). La Biblioteca Digital de la Arquidiócesis de Mérida (Venezuela) y el modelo de metadatos: una propuesta para la difusión de los bienes culturales de la Iglesia católica en la Web. // Scire: Representación y Organización del Conocimiento. 14:2 (jul.-dic. 2008) 131-149.

Sardá Sánchez, Raquel; Sánchez Hernández, María F. (2008). Los procesos de catalogación y difusión de la información en el Museo Cerralbo de Madrid. // Scire: Representación y Organización del Conocimiento. 14:2 (jul.-dic. 2008) 153-160.

Scire. $14: 2$ (jul.-dic. 2008) 9-12. ISSN 1135-3716. 